\title{
Role of ligamentum flavum in the symptomatology of prolapsed lumbar intervertebral discs
}

\author{
P. S. RAMANI, R. H. PERRY, AND B. E. TOMLINSON \\ From the Departments of Neurosurgery and Neuropathology, \\ Newcastle General Hospital, Newcastle upon Tyne
}

SYNOPSIS Hypertrophy of the ligamentum flavum has been reported to occur in the prolapsed intervertebral disc syndrome. The ligaments from 28 patients were compared with a necropsy control group (18). Only minor histological anomalies were noted in two patients and the ligament was not thickened in cases of disc prolapse. In addition, there was no evidence to suggest previous trauma to the ligaments associated with disc protrusion or that the elastic fibres in the ligament degenerate with age, although some degeneration of the collagen fibres had apparently occurred in the two oldest control cases.

Abnormalities of the ligamentum flavum (interlaminar ligament) have been related to the common disorder of low backache and sciatica. During the early years of spinal surgery for prolapsed lumbar intervertebral discs a large number of publications appeared, suggesting that hypertrophy of the ligamentum flavum was a contributory factor in the lumbar disc syndrome (Towne and Reichert, 1931; Abbott, 1936; Hampton and Robinson, 1936; Spurling et al., 1937; Brown, 1938; Meredith and Lehman, 1938; Naffziger et al., 1938; Love, 1939; Jackson, 1948). In none of these reports was the normal anatomy of the ligamentum flavum properly established and compared with pathological material. Again in recent years several reports have appeared restating the theory that hypertrophy of the ligamentum flavum is associated with prolapse of lumbar intervertebral discs (Pickett, 1963; Sicard et al., 1965; Moiel et al., 1967; Paine and Haung, 1972; Yamada et al., 1972). Indeed, Sicard et al. (1965), writing on the surgical anatomy of the ligamentum flavum in patients with sciatica, observed that when the disc was herniated the ligamentum flavum was always hypertrophied, and, conversely, a normal ligament indicated the presence of a normal disc. This view, however,

(Accepted 15 January 1975.) was not fully accepted (Gurdjian et al., 1961 ; Raaf, 1959; Beamer et al., 1973).

In our experience of disc surgery we noted that a thick ligament was not necessarily associated with a prolapsed disc, and in some instances a thin ligament covered a large prolapsed and sequestrated disc. There are no reports of a carefully controlled investigation? comparing the ligamentum flavum in patients with a prolapsed lumbar intervertebral disc and a control group. A prospective comparison was therefore made between the ligamentum flavum of patients operated on for a prolapsed disc (interlaminar approach) and the ligamentum removed under identical conditions from cadavers who had not had symptoms referable to the lumbar spine and in whom no disc prolapses were seen at necropsy. In both groups the ligaments were taken from the lowest two lumbar spaces, as it has been the policy within the surgical unit concerned to explore the two lowest disc spaces, even if on clinical grounds disc prolapse has been suggested at only one level.

\section{METHOD}

Specimens from the interlaminar portion of the ligamentum flavum were obtained from 28 patients operated on for a prolapsed disc. Ninety-five per cent 550 
and $\mathrm{L} 5 / \mathrm{S} 1$. In this series all the ligaments were removed at these levels. In 21 patients the ligaments were removed from one side and in seven from both sides. The age of the patients varied from 17 to 62 years. Under identical conditions, the ligaments from the lowest two lumbar spaces were obtained from 18 cadavers whose ages ranged from 11 years to 82 years.

TABLE

LIGAMENT MEASUREMENTS IN CONTROL AND OPERATIVE GROUPS

\begin{tabular}{|c|c|c|c|c|c|c|}
\hline & \multicolumn{3}{|c|}{$L 4 / L 5$} & \multicolumn{3}{|c|}{$L 5 / S 1$} \\
\hline & \multirow{2}{*}{$\begin{array}{c}\text { Control } \\
(\mathrm{mm})\end{array}$} & \multicolumn{2}{|c|}{ Operative } & \multirow{2}{*}{$\begin{array}{c}\text { Control } \\
(\mathrm{mm})\end{array}$} & \multicolumn{2}{|c|}{ Operative } \\
\hline & & $\begin{array}{c}\text { Normal } \\
\text { disc } \\
(\mathrm{mm})\end{array}$ & $\begin{array}{l}\text { Prolapsed } \\
\text { disc } \\
(\mathrm{mm})\end{array}$ & & $\begin{array}{c}\text { Normal } \\
\text { disc } \\
(\mathrm{mm})\end{array}$ & $\begin{array}{c}\text { Prolapsed } \\
\text { disc } \\
(\mathrm{mm})\end{array}$ \\
\hline & $\begin{array}{r}8 \\
6 \\
6 \\
5 \\
5 \\
6 \\
6 \\
4 \\
8 \\
5 \\
7 \\
6 \\
6 \\
10 \\
4\end{array}$ & $\begin{array}{l}8 \\
6 \\
8 \\
4 \\
5 \\
4 \\
4 \\
5 \\
5 \\
8 \\
6 \\
8 \\
5\end{array}$ & $\begin{array}{r}5 \\
5 \\
7 \\
8 \\
5 \\
4 \\
4 \\
8 \\
5 \\
10 \\
8 \\
7 \\
6 \\
7 \\
8\end{array}$ & $\begin{array}{r}5 \\
6 \\
4 \\
5 \\
4 \\
4 \\
4 \\
3 \\
4 \\
6 \\
10 \\
4 \\
6 \\
5 \\
8 \\
5 \\
4 \\
7\end{array}$ & $\begin{array}{r}7 \\
4 \\
7 \\
5 \\
5 \\
8 \\
10 \\
5 \\
8 \\
8 \\
4 \\
5 \\
6\end{array}$ & $\begin{array}{r}8 \\
6 \\
6 \\
5 \\
3 \\
9 \\
10 \\
4 \\
5 \\
5 \\
4 \\
8 \\
5 \\
4 \\
5 \\
6 \\
8 \\
3\end{array}$ \\
\hline \multirow[t]{2}{*}{$\begin{array}{l}\text { Number } \\
\text { Mean (mm) } \\
\text { SD } \\
\text { Range (mm) }\end{array}$} & $\begin{array}{l}15 \\
6.13 \\
1.59 \\
4-10\end{array}$ & $\begin{array}{l}13 \\
5.85 \\
1.62 \\
4-8\end{array}$ & $\begin{array}{l}15 \\
6.47 \\
1.76 \\
4-10\end{array}$ & $\begin{array}{l}18 \\
5.22 \\
1.73 \\
3-10\end{array}$ & $\begin{array}{l}13 \\
6.31 \\
1.84 \\
4-10\end{array}$ & $\begin{array}{l}18 \\
5.78 \\
2.04 \\
3-10\end{array}$ \\
\hline & \multicolumn{3}{|c|}{ Combined } & \multicolumn{3}{|c|}{ Combined } \\
\hline $\begin{array}{l}\text { Number } \\
\text { Mean (mm) } \\
\text { SD } \\
\text { Range (mm) }\end{array}$ & \multicolumn{3}{|c|}{$\begin{array}{l}28 \\
6.18 \\
1.70 \\
4-10\end{array}$} & \multicolumn{3}{|c|}{$\begin{array}{r}31 \\
6.00 \\
1.94 \\
3-10\end{array}$} \\
\hline
\end{tabular}

After excision the inner surface of the ligament was marked with a stitch and the tissue fixed in $10 \%$ formol saline. After fixation the inner edge was marked with ink. All the ligaments were sectioned in the longitudinal (vertical) plane. In order to assess any variation in histological appearance, a number of ligaments were also sectioned transversely. The thickness was measured from the inner to the outer border on the fixed specimen. In cases where disruption of the ligament made precise measurements of the width difficult, the broadest part of the ligament was taken to be the width. In those cases where the cross-section was triangular the maximum width was measured.

The following staining procedures were used: all sections were stained by haematoxylin and eosin and by aldehyde fuschin with light green as a counterstain, the latter being preferred to the elastic van Gieson procedure because of the tendency for the ligaments to lift off the slide during staining. Periodic acid Schiff (PAS) was used on selected control cases and on all operative ligaments.

The sections stained with aldehyde fuschin were used for determining the total quantity, position, and structural formation of the elastic tissue in the ligaments. Vertical sections (sections cut in the long axis) of the ligament were used for this quantitative assessment of elastic tissue, the latter being performed by one observer on sections which were not identifiable as control or operative specimens. Some transverse sections were used to obtain further information on the structural formation of the fibres. The content of elastic tissue was expressed as a percentage of the thickness of the ligament from its inner to outer border. If elastic tissue constituted the inner half of the ligament it was recorded as being $50 \%$. If more or less elastic tissue was present the percentage was suitably adjusted.

\section{RESULTS}

L4/L5 LEVEL In the control group 15 ligaments were obtained with a mean thickness of $6.13 \mathrm{~mm}$ (SD 1.59) (Table). In the operative group 28 ligaments were obtained with a mean thickness of $6.18 \mathrm{~mm}$ (SD 1.70). Fifteen of these latter ligaments were associated with an underlying prolapsed disc and their mean thickness was 6.47 $\mathrm{mm}$ (SD 1.76). There is no significant difference between the control group and the total operative group or between the control group and those ligaments which were associated with an underlying prolapsed disc.

L5/S1 LEVEL Eighteen ligaments at this level in the control group had a mean thickness of 5.22 $\mathrm{mm}$ (SD 1.73). Thirty-one operative specimens were obtained, mean $6.0 \mathrm{~mm}$ (SD 1.94) and 18 of these were associated with an underlying prolapsed disc, mean $5.78 \mathrm{~mm}$ (SD 2.04). There is, again, no significant difference between the control group, the operative group and those ligaments associated with an underlying prolapsed disc. 


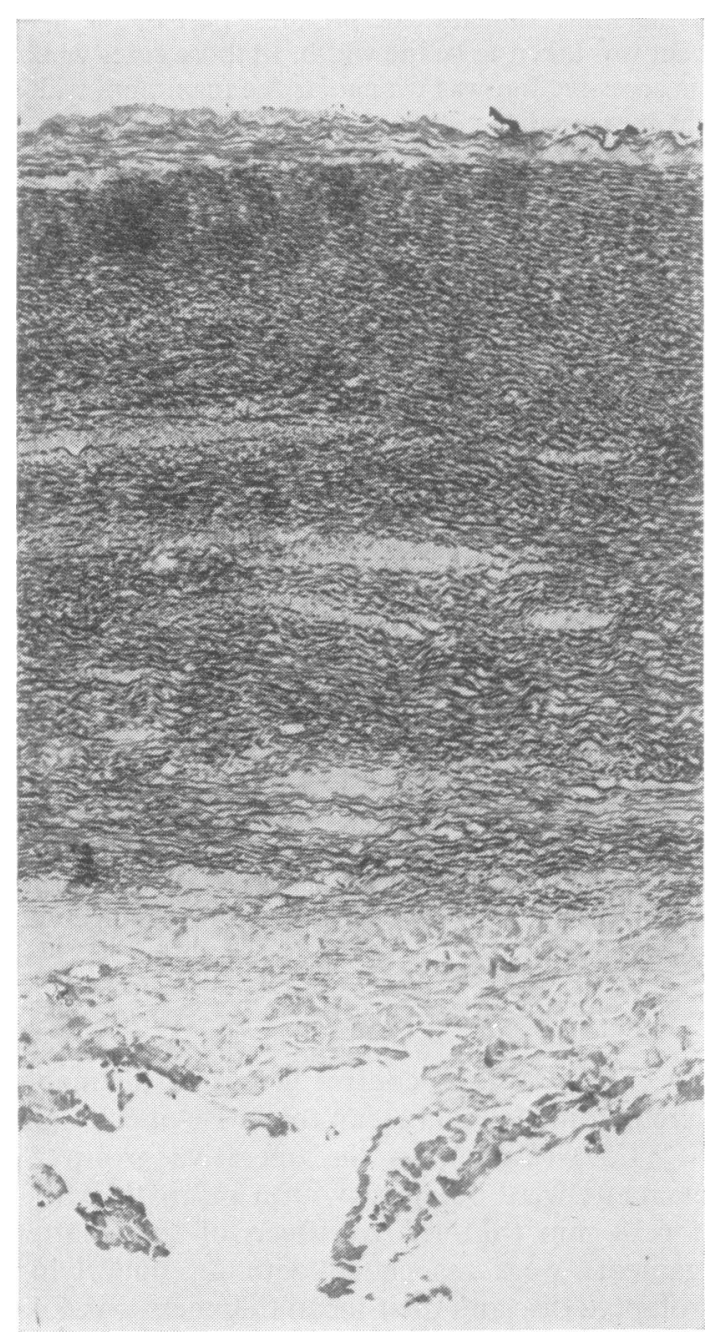

FIG. 1 The normal ligamentum flavum with an inner elastic and outer collagen layer. Small blood vessels are identifiable at the elastic collagen junction. The elastic tissue in this section would be estimated as $75 \%$ of the total. Aldehyde fuschin, $\times 45$.

ELASTIC TISSUE CONTENT The elastic fibre content of the ligament was estimated in the manner described previously. The mean percentage of the elastic tissue in the control group was 50 (SD 14.2). In the operative group the mean percentage was 53 (SD 12.7). This is in reasonable agreement with Evans and Nachenson (1969) who assayed the elastic content chemically and

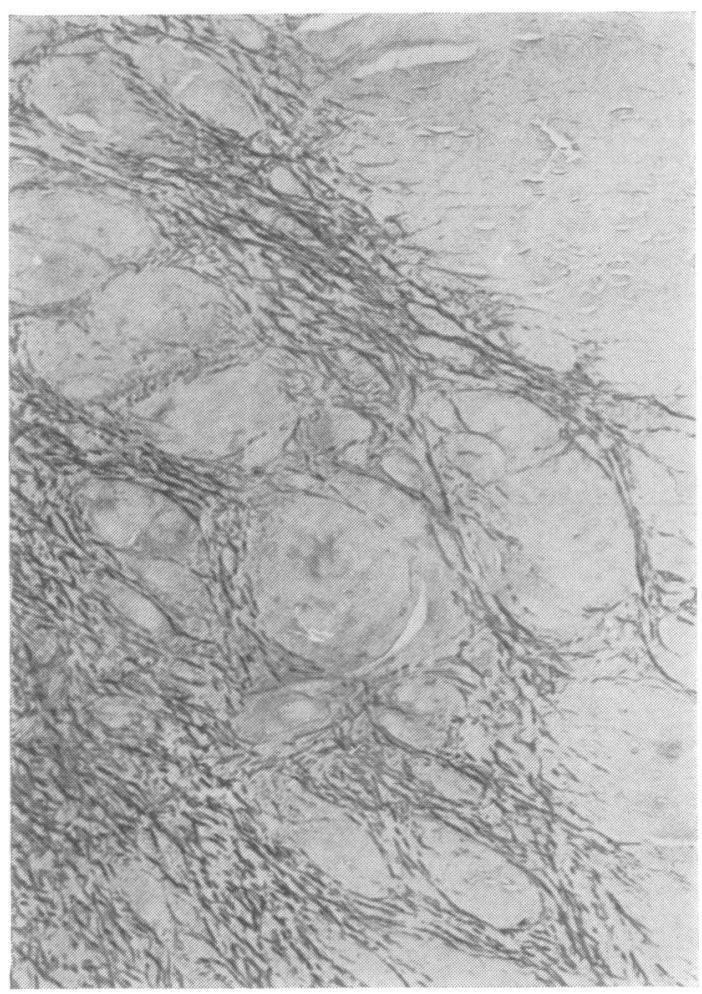

FIG. 2 Illustrating the circular collagen bundles at the elastic collagen junction. Aldehyde fuschin, $\times 110$. (Elastic fibres black.)

found it to be $50-60 \%$. In those ligaments with an underlying prolapsed disc the percentage of elastic tissue was not significantly different from that of the total operative group. Analysis of the elastic content in relation to age (in decades) revealed no significant differences.

HISTOLOGICAL FEATURES In general the previous histological description of the ligament was confirmed (Sicard et al., 1965; Ramsey, 1966). The ligament consists of a mixture of elastic tissue and collagen. The elastic tissue is present as compact, interlaced, and undulating fibres which are normally orientated in a vertical direction parallel to the inner border of the ligament. The width of the elastic band is variable. It generally represents at least a quarter of the total thickness but occasionally constitutes almost the entire thickness of the ligament. A 


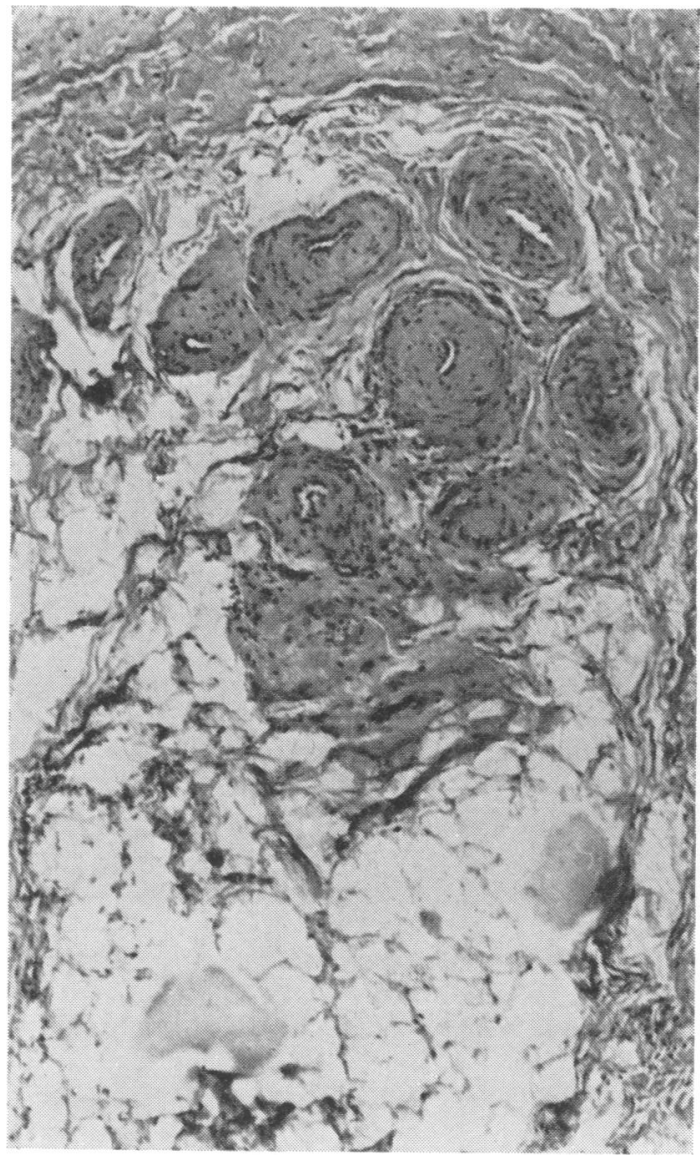

FIG. 3 A group of thick-walled blood vessels, accompanied by fat, in the collagen layer close to the elastic tissue. $H$ and $E, \times 64$.

thin layer of collagen containing small blood vessels is frequently present at the inner edge of the ligament. Bands of collagen are often seen in the elastic tissue giving rise to a laminated appearance of alternating elastic and collagen layers (Fig. 1). Both fibres intermingle at the elastic/ collagen junction and in this area circular bundles of collagen fibres are distributed in elastic tissue to produce the characteristic crosssectional appearance shown in Fig. 2. The outer collagen layer is less compact than the elastic tissue and has a less uniform appearance. The fibres are arranged as homogeneous bands, as circular bands 50 to $100 \mu \mathrm{m}$ in diameter, and as

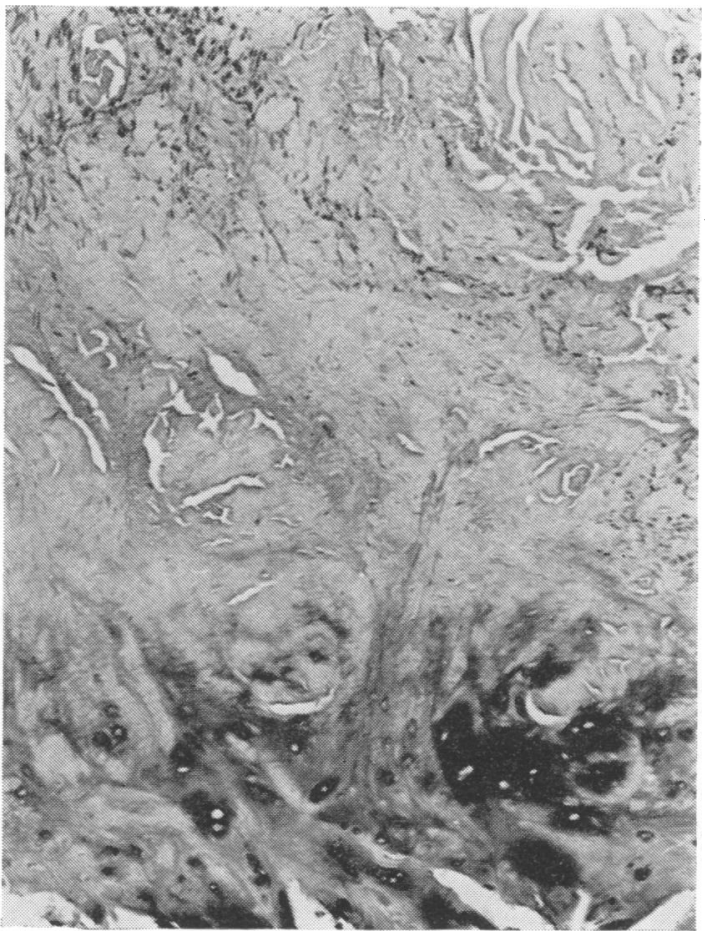

FIG. 4 The ligamentum flavum at the lamina border. Bone is present in the lower half of the picture. Apparent fragmentation of the collagen bundles is a processing artefact. Aldehyde fuschin, $\times 64$.

a series of irregular interlacing bundles interspersed with areolar tissue.

Variable quantities of fat cells are present, particularly on the outer border of the ligament and around blood vessels (Fig. 3). The majority of blood vessels lie in the collagen layer or as a 'vascular plane' at the elastic/collagen junction. In the latter region the vessels are often seen as groups of thick-walled arterioles and veins (Fig. 3). Smaller vessels and capillaries, often associated with surrounding collagen, are present in the elastic tissue and at the inner border of the ligament. At the edge of the ligament cartilaginous tissue, fibrous tissue and bone occasionally mark the site of attachment of the ligament to the vertebral lamina (Fig. 4). In the operative cases fresh haemorrhage is often present at this edge. Muscle fibres may be attached to the outer border of the ligament. This description applied to the majority of ligaments in the control and 


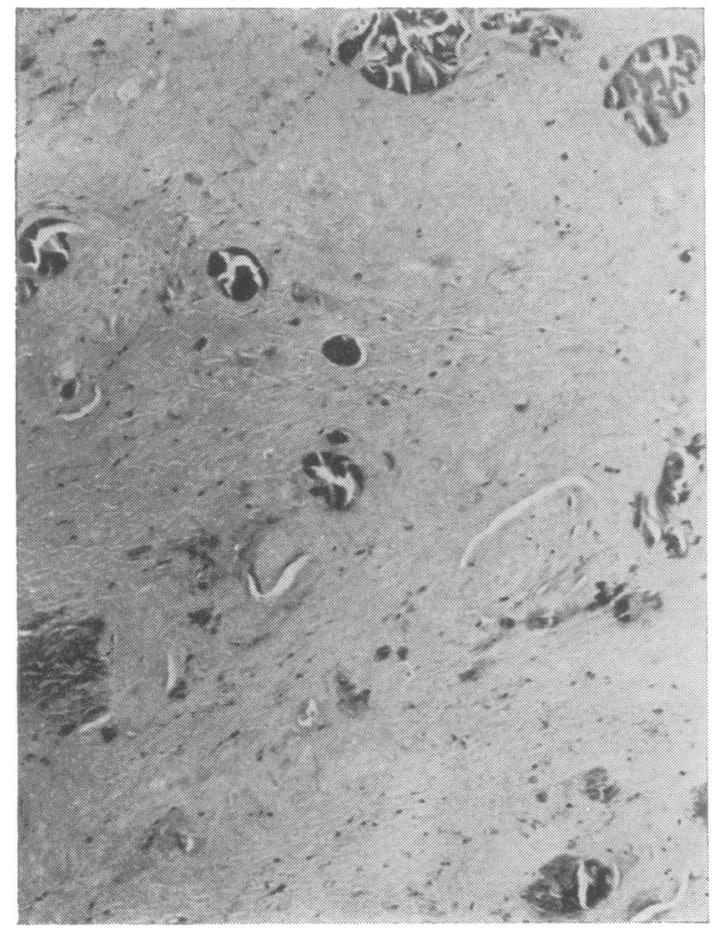

FIG. 5 Collagen bundles staining positively with PAS in the collagen layer of an 82 year old control. PAS, $\times 64$.

operative groups. Other histological features are described below:

Injury Rupture or overstretching of the ligament during life would be expected to fragment or disrupt fibres, tear blood vessels, and cause haemorrhage. Any resulting haematoma would be absorbed and organized as haematomas elsewhere, remaining identifiable as areas of scar tissue with or without inflammatory cells, haemosiderin pigment, or calcium salt deposition. In the elastic tissue none of these features was seen in any ligament. In the collagen, disruption of the architecture is not as readily appreciated as in the elastic layer because the arrangement of the fibres is more haphazard. Nevertheless, nothing suggestive of scar tissue was identified in this layer. No foci of inflammatory cells, macrophage collections, calcification, or haemosiderin deposition were identified.

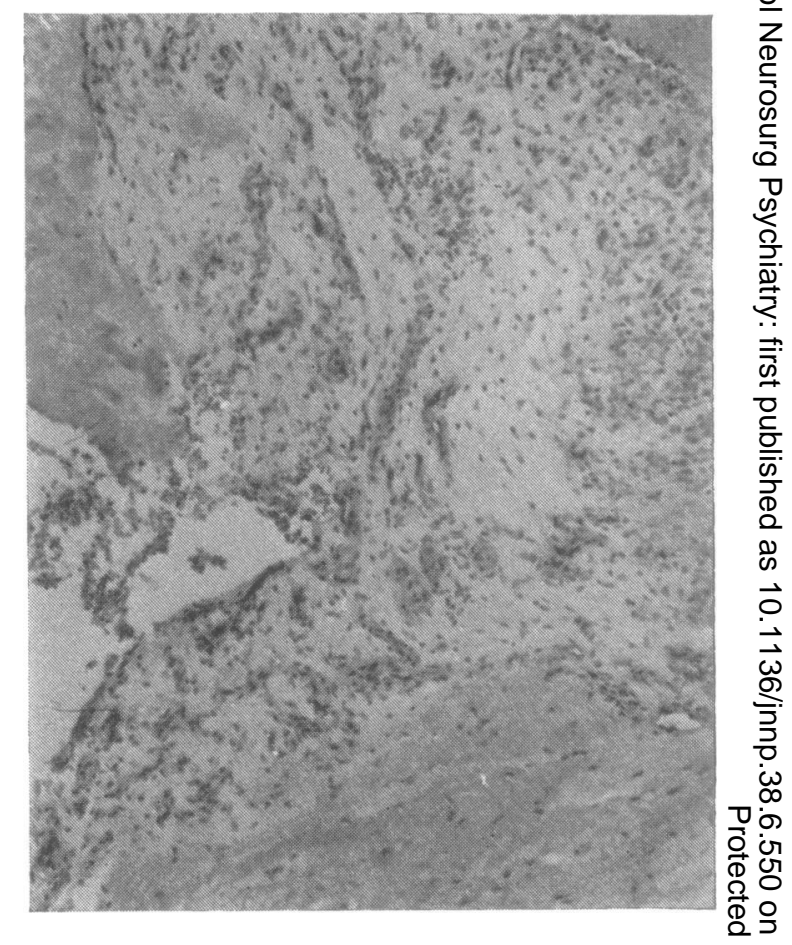

FIG. 6 Endothelial proliferation and fibroblast $\vec{C}$ activity at the edge of a ligament in a 55 year old $\varnothing$ patient with a prolapsed disc. $H$ and $E, \times 110$.

Degenerative changes In connective tissue the common form of degenerative lesion which occurs is identifiable as a hyaline or mucoid change in the fibres. More extensive degenerative changes result in necrosis, fibrosis, calcification, and cyst formation. Endothelial proliferation often occurs at the edge of a degenerate area. In the two oldest cases (70 years and 82 years) groups of collagen fibres stained more intensely with eosin than the surrounding tissue. These fibres were PAS positive which suggests that they were degenerative in nature (Fig. 5). In the operative group there were no similarly staining fibres. Endothelial proliferation was present at the site of the attachment of the ligament to the lamina in two cases. Both ligaments were associated with a prolapsed disc. In the first case, a male aged 55 years, the surrounding collagen (not elastic) fibres were degenerate (Fig. 6). This ligament was not thickened $(6 \mathrm{~mm})$ and had a slightly reduced content of elastic tissue $(40 \%)$ 


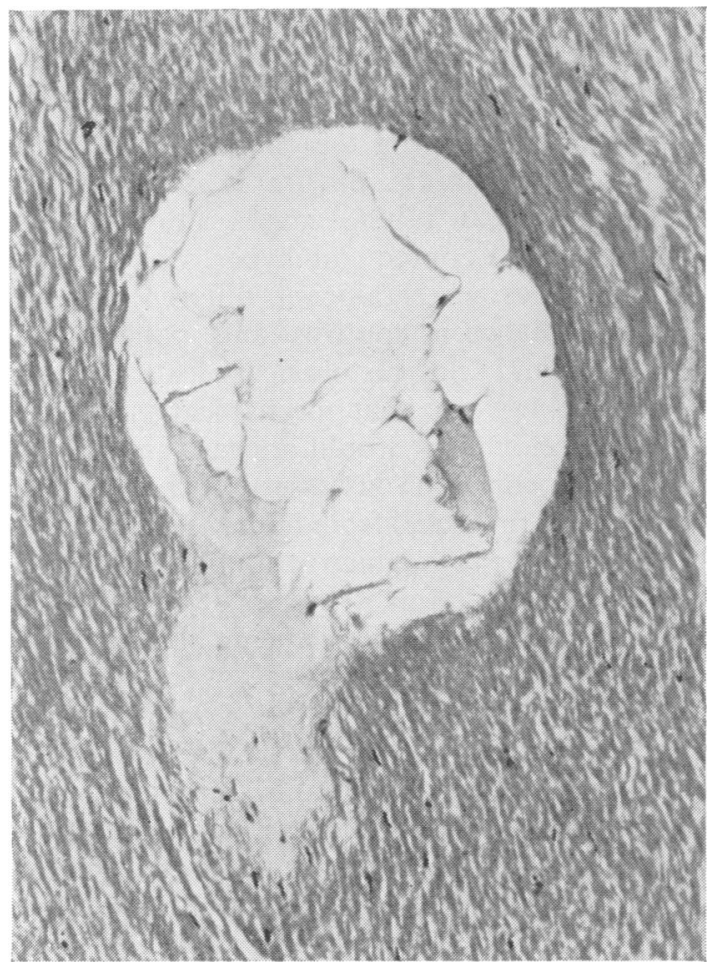

FIG. 7 Cystic cavity in the elastic tissue. Aldehyde fuschin, $\times 200$.

compared with the mean of the series $(54 \%)$. In the second case, a male of 43 years, a circular area of blood vessels showing endothelial proliferation had occurred at the outer border of the collagen layer. This ligament was $8 \mathrm{~mm}$ thick and had no other abnormalities. In the control series no such areas of endothelial proliferation were seen.

A cystic space was present in the elastic tissue of one ligament removed at operation. The patient was 45 years old and the ligament was associated with a prolapsed disc. The cyst was approximately $200 \mu \mathrm{m}$ in diameter and was not at the elastic/collagen junction. It contained thick strands of hyalinized material with no peripheral cell lining and the content did not stain with PAS, Alcian blue, or lipid stains (Fig. 7).

A pseudocystic appearance may be produced artificially at the elastic/collagen junction.

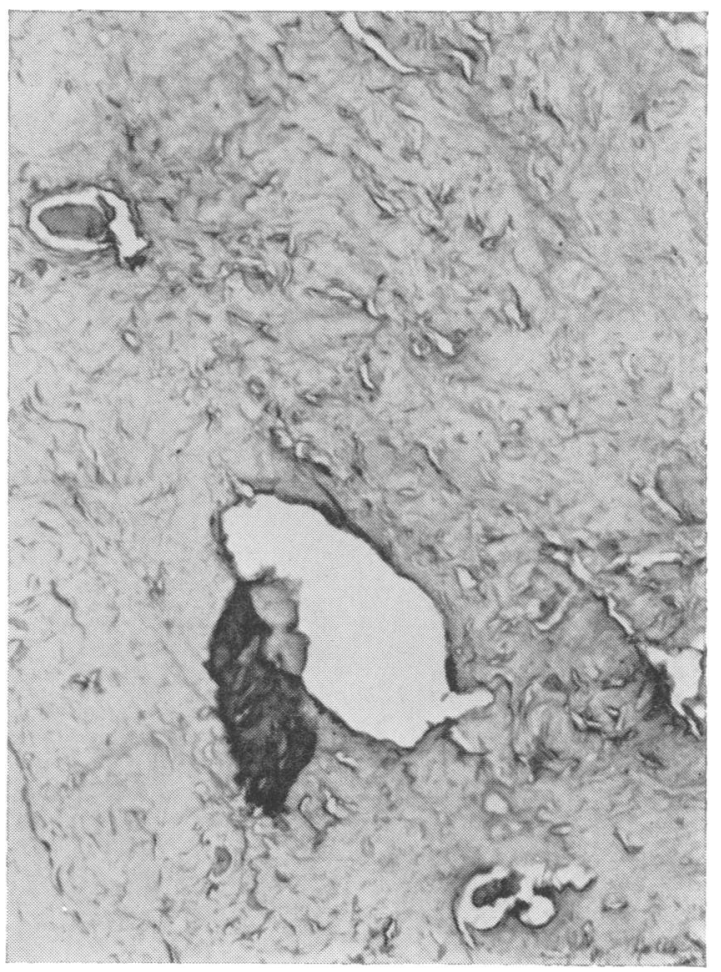

FIG. 8 A collagen bundle partially displaced in the collagen layer. A pseudocystic appearance may result. Aldehyde fuschin, $\times 180$.

Circular bands of collagen are present in this region and during sectioning of the paraffin block they may be displaced (Fig. 8). Hyalinized vessels were not infrequently seen (Fig. 9). They were present in control and operative ligaments in cases over 40 years of age and were not associated with any other visible abnormality or with systemic disease such as hypertension, diabetes, or collagen disorders. Groups of thickwalled vessels were present in the collagen tissue of control and operative material. Their significance is discussed below.

\section{DISCUSSION}

In an investigation of the pathology of the ligamentum flavum, it is obviously critical that a normal ligamentum flavum is described pre- 


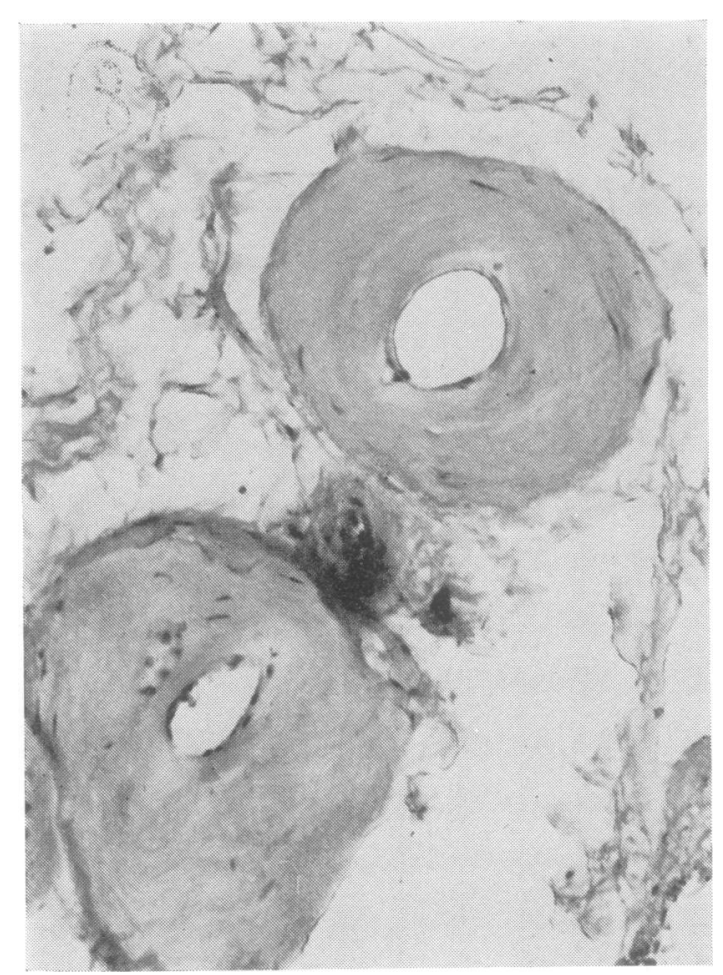

FIG. 9 Hyalinized blood vessels at the edge of a ligament. $H$ and $E, \times 160$.

cisely. From the results of this study, the normal thickness of the interlaminar portion at the lower lumbar disc spaces has been established as follows: (1) at the level of L4/5 disc the thickness lies between 4 and $10 \mathrm{~mm}$ with a mean value of $6.13 \mathrm{~mm}$; (2) at the lowest lumbar space, L5/S1, the thickness lies between $3 \mathrm{~mm}$ and $10 \mathrm{~mm}$ with a mean value of $5.2 \mathrm{~mm}$. The mean thickness at these two levels, $6.13 \mathrm{~mm}$ and $5.2 \mathrm{~mm}$, is in reasonable agreement with reported measurements made in more recent investigations-for example, Ramsey (1966) (4-6 mm), and is larger than reported in the series of Horwitz (1939) (3.8 $\mathrm{mm}$ and $3.6 \mathrm{~mm}$ ) and of Spurling et al. (1937) $(4.4 \mathrm{~mm}$ and $4.2 \mathrm{~mm})$. In these investigations, however, it is not stated if the ligament thickness was measured before fixation, after fixation or after embedding. The range of thickness found in this study is greater than that reported by earlier workers; Spurling et al. $2 \mathrm{~mm}-7 \mathrm{~mm}$ and Horwitz $1.5 \mathrm{~mm}-6 \mathrm{~mm}$. It is probable that where a supposed hypertrophied ligament has been observed in connexion with a prolapsed disc allowance has not been made for normal variation in thickness.

In work supporting the concept of a hypertrophied ligamentum flavum it is maintained that mechanical injury causes fibrous tissue formation and consequent hypertrophy. In the present series no significant difference in the thickness between controls and patients was observed and no histological features were present to indicate that mechanical injury had taken place. Thus it would appear that Ramsey (1966) was correct in his assertion that the ligament is well protected from injury. Ramsey does, however, refer to a 'micro trauma of function' which he suggests gives rise to degeneration in the elastic tissue and consequent fibrosis. In all the ligaments examined in this work, with the exception of one, the elastic tissue was apparently free of degenerative change or fibrosis and the elastic content did not diminish with age. In the exceptional case a cystic cavity was present in the elastic layer. No other features of degeneration were present and since the finding was isolated it is unlikely to be of great significance.

The ligaments of two elderly controls contained abnormally stained collagen bundles in the collagen layer. This almost certainly represents fibre degeneration. Since degeneration of this nature was observed only in the two oldest cases it would appear to be related to age rather than to traumatic disruption. Although the ligament was not thickened and although there was no evidence of past traumatic damage, two patients with disc prolapse showed areas of endothelial proliferation in the collagen layer. There were no other histological features to suggest that trauma had occurred and the presence of collagen necrosis in one of these cases suggests that degenerative change had taken place. At the present time the significance of the endothelial proliferation in the collagen layer is unknown.

Although ligament calcification has been regarded as pathological (Spurling et al., 1937), in this series it was present only at the junction of the ligament with the bony lamina. As noted previously, groups of thick walled (not hyalinized) vessels are present in the collagen layer, and are not specifically related to any group. Spurling et al. (1937) associated them with previous 
inflammation in spite of the absence of inflammatory change. It may be that the thickened vessel walls maintain vessel patency when the ligament is stretched and it is pertinent that similar groups of thick-walled vessels are present in muscles and ligaments elsewhere and appear as a normal histological feature.

In attempting to relate histological features to mechanical function it is of interest that the collagen layer has a loose arrangement compared with the compact elastic tissue layer. Collagen fibres are relatively inextensible compared with elastic fibres but have approximately 10 times their tensile strength (Florey, 1970). The ligamentum flavum has a restricted extensibility (Nunley, 1958), extending to between $30-50 \%$ of its original length. When the ligament is stretched it is reasonable to suppose that the collagen layer becomes taut and limits extension beyond a certain point. If, as other authors have suggested, fibrous tissue replaces connective tissue in the ligamentum flavum as a consequence of degeneration or trauma, the mechanical properties would be altered considerably. As fibrous tissue is inextensible, the ligamentum flavum would no longer be capable of normal extension and retraction. Flexion in the lower lumbar vertebrae would thus be restricted. In patients who recover from an episode of disc prolapse, and where pain is totally relieved, the lumbar flexion returns to normal. This is consistent with the fact that no evidence of fibrous tissue replacement of elastic tissue has been found.

In conclusion, it has been established that the ligamentum flavum is not significantly thickened in patients who have a prolapsed lumbar intervertebral disc compared with a control group. The elastic tissue did not decrease with age as other authors have suggested and only minor histological anomalies were seen in two cases with a prolapsed disc. On morphological grounds, therefore, there is no evidence that the ligamentum flavum contributes to the development of the syndrome of prolapsed lumbar intervertebral disc.

\section{REFERENCES}

Abbott, W. D. (1936). Compression of the cauda equina by the ligamentum flavum. Journal of the American Medical Association, 106, 2129-2130.
Beamer, Y. B., Garner, J. T., and Shelden, C. H. (1973). Hypertrophied ligamentum flavum. Archives of Surgery, 106, 289-292.

Brown, H. A. (1938). Enlargement of the ligamentum flavum: a cause of low-back pain with sciatic radiation. Journal of Bone and Joint Surgery, 20, 325-338.

Evans, J. H., and Nachemson, A. L. (1969). Biomechanical study of human lumbar ligamentum flavum. Journal of Anatomy, 105, 188-189.

Florey, H. W. (1970). General Pathology, 4th edn, pp. 457459. Lloyd-Luke: London.

Gurdjian, E. S., Ostrowski, A. Z., Hardy, W. G., Lindner, D. W., and Thomas, L. M. (1961). Results of operative treatment of protruded and ruptured lumbar discs. Journal of Neurosurgery, 18, 783-791.

Hampton, A. O., and Robinson, J. M. (1936). The roentgenographic demonstration of rupture of the intervertebral disc into the spinal canal after the injection of lipiodol, with special reference to unilateral lumbar lesions accompanied by low back pain with 'sciatic' radiation. American Journal of Roentgenology, 36, 782-803.

Horwitz, T. (1939). Lesions of the intervertebral disk and ligamentum flavum of lumbar vertebrae. An anatomic study of 75 human cadavers. Surgery, 6, 410-425.

Jackson, H. (1948). The association between certain anatomical facts, normal and morbid, and the symptomatology of intervertebral disc protrusions in the lumbar region. Annals of the Royal College of Surgeons of England, 2, 273-284.

Love, J. G. (1939). Protruded intervertebral disks, with a note regarding hypertrophy of ligamenta flava. Journal of the American Medical Association, 113, 2029-2034.

Meredith, J. M., and Lehman, E. P. (1938). Hypertrophy of the ligamentum flavum. Surgery, 4, 587-596.

Moiel, R. H., Ehni, G., and Anderson, M. S. (1967). Nodule of the ligamentum flavum as a cause of nerve root compression. Case report. Journal of Neurosurgery, 27, 456-458.

Naffziger, H. C., Inman, V., and Saunders, J. B. de C. M. (1938). Lesions of the intervertebral disc and ligamenta flava. Surgery, Gynecology and Obstetrics, 66, 288-299.

Nunley, R. L. (1958). The ligamenta flava of the dog. A study of tensile and physical properties. American Journal of Physical Medicine, 37, 256-268.

Paine, K. W. E., and Haung, P. W. H. (1972). Lumbar disc syndrome. Journal of Neurosurgery, 37, 75-82.

Pickett, J. C. (1963). The lumbar ligamentum flavum in low back and sciatic pain. Southern Medical Journal, 56, 10361042.

Raaf, J. (1959). Some observations regarding 905 patients operated upon for protruded lumbar intervertebral disc. American Journal of Surgery, 97, 388-399.

Ramsey, R. H. (1966). The anatomy of the ligamenta flava. Clinical Orthopaedics, 44, 129-140.

Sicard, A., Batisse, F., and Dahbar, H. (1965). Anatomie chirurgicale du ligament jaune et du disque intervertébral dans les sciatiques. Presse Médicale, 73, 325-329.

Spurling, R. G., Mayfield, F. H., and Rogers, J. B. (1937). Hypertrophy of the ligamenta flava as a cause of low back pain. Journal of the American Medical Association, 109, 928-933.

Towne, E. B., and Reichert, F. L. (1931). Compression of the lumbosacral roots of the spinal cord by thickened ligamenta flava. Annals of Surgery, 94, 327-336.

Yamada, H., Ohya, M., Okada, T., and Shiozawa, Z. (1972). Intermittent cauda equina compression due to narrow spinal canal. Journal of Neurosurgery, 37, 83-88. 